\title{
Charge Coupled Devices as Particle Detectors
}

\author{
Dan A. Iordache, ${ }^{1,2}$ Paul E. Sterian, ${ }^{1,2}$ and Ionel Tunaru ${ }^{1}$ \\ ${ }^{1}$ Physics Department, University "Politehnica" of Bucharest, 313 Splaiul Independentei, 060042 Bucharest, Romania \\ ${ }^{2}$ Section of Science and Technology of Information, Academy of Romanian Scientists, 54 Splaiul Independentei, \\ 050094 Bucharest, Romania
}

Correspondence should be addressed to Ionel Tunaru; tunaru_ionel@yahoo.fr

Received 1 October 2012; Accepted 10 February 2013

Academic Editor: Jacek Szabelski

Copyright (C) 2013 Dan A. Iordache et al. This is an open access article distributed under the Creative Commons Attribution License, which permits unrestricted use, distribution, and reproduction in any medium, provided the original work is properly cited.

\begin{abstract}
As it is well known, while the most important advantages of the charge coupled devices, as high energy particle detectors are related to their (a) extremely high sensitivity (very important for the underground laboratories, also) and (b) huge number of very small independent components (pixels) of the magnitude order of $10^{6}$, which allow the separate impressions of many different "signatures" of (silicon lattice defects produced by) these particles, their main disadvantages refer to the (a) difficulty to distinguish between the capture traps (of free electrons and holes, resp.) produced by the radiation particles and the numerous types of traps due to the contamination or dopants and (b) huge number of types of lattice defects due to the irradiation. For these reasons, this work achieves a state of art of the (i) main experimental methods and (ii) physical parameters intended to the characterization of the main types of traps embedded in the silicon lattice of CCDs. There were identified also some new physical parameters useful in this aim, as the polarization degree of capture cross-sections and the state character, as well as some new useful notions, as the trans-Fermi level capture states.
\end{abstract}

\section{Introduction}

As it was shown by the classical scientific monographs $[1,2]$ on the charge coupled devices (CCDs), the silicon quality is extremely critical for the CCD sensors/detectors. Impurities as gold, transition metals, or lattice imperfections can have a profound effect on CCD performance. One of the most important chapters of the main scientific monograph [1] on CCDs (the last one, 125 pages) and other 18 pages (from the total of 24 pages) of final Appendices are dedicated to the radiation damage.

One finds the specific effects on silicon of fluxes of photons, electrons, muons, pions, protons, deuterons, helium ions, and so forth [1, page 814]. The most important effects of the protons fluxes refer to the divacancy electron $\left(E_{c}-0.39 \mathrm{eV}\right.$, $\left.\sigma_{n}=4 \cdot 10^{-15} \mathrm{~cm}^{2}\right)$ and holes traps $\left(E_{v}+0.21 \mathrm{eV}, \sigma_{p}=2\right.$. $\left.10^{-16} \mathrm{~cm}^{2}\right)$, as well as to some combinations of vacancies with certain dopants, as the P-V center (the so-called E-centers: $E_{c}-0.45 \mathrm{eV}, \sigma_{n}=3.7 \cdot 10^{-16} \mathrm{~cm}^{2}$ ) and As-V or O-V center (the so-called A-centers: $E_{c}-0.175 \mathrm{eV}, \sigma_{n}=1 \cdot 10^{-14} \mathrm{~cm}^{2}$ ); see, for example, $[1,3]$. As it results from the works [4-6], the number of trap types induced by nuclear irradiation is huge (more than 600 types only for the low energy He ion bombardment; e.g., the main physical parameters of the EHe584 trap type are [4] $\left.E_{c}-0.58 \pm 0.03 \mathrm{eV}, \sigma_{n}=(1.0 \pm 0.5) \cdot 10^{-15} \mathrm{~cm}^{2}\right)$.

The specialty literature involves also a rather large number of nanoimpurities and nanodefect types that can affect the quality of the silicon crystalline lattice. The study of these nanoimpurities and defects began even before (see, e.g., [724]) the invention (in 1969) of the charge coupled devices, "culminated" with the elaboration of the main experimental methods used to identify and characterize them [25-38], and continues nowadays (see, e.g., [39-41]). The CCDs image sensors are extremely sensitive to contamination by heavy metals, which form Shockley-Reed-Hall deep-level traps that generate dark current in the imager region of the silicon device $[28,32]$. This dark current from defects scattered among the imager pixels represents a source of pattern noise and may cause the pixels and even the imager to be defective. The deep-level transient spectroscopy (DLTS [25-27]) and 
the dark current spectroscopy (DCS, [28-38]) methods allow the study of these deep-level traps in silicon at concentrations even of only $10^{7}$ nanotraps $/ \mathrm{cm}^{3}$.

Taking into account the complex character of semiconductors, they are described by a huge number of uniqueness parameters. In fact, the existing nonnegligible measurement errors allow accurate evaluations only for few dominant uniqueness parameters, specific to the physical processes characteristic to a certain experimental method. For this reason, the achievement of some sufficiently complete physical characterizations of the nanoimpurities and/or nano-defects of a semiconductor lattice requires the use of two or more complementary measurement methods.

\section{Short Review of the Main Experimental Methods Used to Characterize the Nanoparticles, Nanocomplexes, and/or Defects Embedded in the Si Lattice}

The physical characterization of the impurities and/or defects from semiconductors presents a special importance for the design and use of various semiconductor devices, as the charge coupled devices $[1,2]$, the semiconductor solar cells [42-46], and so forth. Taking into account the complex nature of many semiconductors, the number of their characteristic parameters is huge; hence usually only a unique experimental method is not able to provide a complete description of semiconductors.

The most important experimental methods intended to the study of the energy levels of the impurities and/or defects from semiconductors belong mainly to 3 classes: (A) spectroscopic methods, (B) electrical methods, and (C) nuclear methods.

The most important experimental methods of the first class are those of the (A1) electron paramagnetic resonance (EPR, used firstly in [7-9]) and (A2) luminescence (used to identify the shallow impurities or defects, see, e.g., [10]).

Similarly, the main electrical methods can be classified as (B1) the classical electrical techniques, as those of the (B1a) temperature dependence of the resistivity (e.g., works $[11,12]$ ) and the (B1b) Hall effect (see works $[13,14]$ ) and (B2) Junction techniques, of the types (B2a) non-transient techniques as the (i) admittance spectroscopy (see, e.g., [15]) and (ii) the thermally stimulated capacitance (TSCa, used by [16-19]) and (B2b) transient techniques, as the (i) p/n or Schottky junctions technique (e.g., [20-22]), (ii) capacitance and current transients [23], the (iii) photocapacitance, particularly [24], and (iv) deep-level transient spectroscopy (DLTS), with its basic work [25], and some of its first applications [26, 27], and the (f) dark current spectroscopy (DCS).

As it results from Table 1, the most important versions of the dark current spectroscopy are (i) the classical one (basic work [28], and some of its most important applications [14b-14f]), (ii) the DCS computational approach (represented mainly by the works leading to the evaluation of the (iia) preexponential factors of the diffusion and depletion dark currents [36-38], (iib) activation energy [47, 48], as well as the study of the: (iic) Meyer-Neldel corelations [49-51], (iid) choice and evaluation of the basic uniqueness parameters [5254], and (iie) hidden corelations in complex semiconductors $[55,56])$.

The most important nuclear methods are the $(\mathrm{C} 1)$ neutron activation analysis (e.g., the works [57-61]), (C2) tracers method (for some of its main works, see [62-66]), (C3), (C3) nuclear irradiation methods (e.g., $[39,67,68])$.

The thorough study of the specialty literature points out that besides the dark current spectroscopy method, the most important experimental methods intended to the characterization of impurities and/or defects from semiconductors are the DLTS method (especially) and the TSCa one. For the above indicated reasons, many experimental works report the results obtained by means of both (a) DLTS and TSCa methods (e.g., [69-71]), (b) DLTS and EPR [72, 73], (c) DLTS and Hall [74], (d) Hall and EPR methods [75, 76], and so forth. We have to underline that the DLTS method allows to (a) point out the character (acceptor or donor, resp.) of the impurity/defect state, (b) evaluate (i) its absolute position (energy) and (ii) the capture cross-sections corresponding to the free electrons $\left(\sigma_{n}\right)$ and holes $\left(\sigma_{h}\right)$, respectively.

Additionally, the basic DLTS work [25] achieves a detailed comparison of this method with the capacitance techniques (TSCa, AST, and photocapacitance), while the works [77] (for the electrical data) and [78] (for the basic features of deeplevel states of the transition metals in $\mathrm{Si}$ ) achieve some of the most important state of art (reviews) of the basic methods and results from this field (more than 400 citations of the work [78]).

Other detection procedures of the cosmic rays and the mathematical models of the corresponding dissipative systems were studied in the frame of the works $[79,80]$.

\section{Theoretical Part: The Main Sources of Dark Current}

The most important sources of dark current in semiconductors are [1, pages 605-648], [2, pages 37-45] (a) the field-free regions (diffusion and substrate (dominant for very heavily doped (> 1017 $\mathrm{cm}^{-3}$ ) semiconductors)) dark current, (b) the depletion (or bulk) dark current generated in the depletion region, and (c) the surface dark current generated at the Si$\mathrm{SiO}_{2}$ interface. If the CCD is operated in a multipinned phase (MPP) mode, then the interface is completely inverted with a high hole carrier concentration, hence the surface dark current from the $\mathrm{Si}-\mathrm{SiO}_{2}$ interface will be almost completely suppressed. The analysis of the field-free regions (diffusion and substrate) and depletion dark current, respectively, was achieved in the frame of various books on semiconductors, the more important being those of Grove [81] and Sze [82].

3.1. The Depletion Dark Current. Taking into account that the parameters of nanoparticles influence the dark current, we will study the contribution of the depletion processes to the dark current, given [36] by the expression (the present validity and usefulness of the Shockley-Read-Hall (SRH) 
model and statistics were confirmed also by the several recent studies (see, e.g., $[46,93])$ :

$$
D e_{\mathrm{SRH}}^{-}=-\frac{x_{\mathrm{dep}} \cdot n_{i}^{2} \cdot A_{\mathrm{pix}}}{U},
$$

where the net generation-recombination rate $U$ corresponding to the impurities and/or imperfections of the semiconductor lattice is described by the following relation (At thermal equilibrium: $n \cdot p=n_{i}^{2}$, hence $U_{\mathrm{dep}}=0$ (the recombination and generation rates being equal)):

$$
U=\frac{\sigma_{p} \sigma_{n} V_{t h}\left(n \cdot p-n_{i}^{2}\right) N_{t}}{\sigma_{n}\left[n+n_{i} \exp \left(\left(E_{t}-E_{i}\right) / k T\right)\right]+\sigma_{p}\left[n+n_{i} \exp \left(\left(E_{i}-E_{t}\right) / k T\right)\right]} .
$$

In the above expressions, $x_{\mathrm{dep}}$ is the width of the depletion layer, $A_{\text {pix }}$ is the pixel area, $\sigma_{p}, \sigma_{n}$ are the capture crosssections for holes and electrons, respectively, $V_{\text {th }}$ is the thermal velocity, $E_{i}$ is the intrinsic Fermi energy level, $N_{t}$ is the concentration of traps, that is, of bulk generationrecombination centers at the energy level $E_{t}$, while $n, p$, and $n_{i}$ are the electrons, the holes, and the intrinsic carrier concentration, respectively, given by the expressions

$$
\begin{gathered}
n=2\left(\frac{2 \pi \cdot m_{n} k T}{h^{2}}\right)^{3 / 2} \exp \frac{\mu-E_{c}}{k T}, \\
p=2\left(\frac{2 \pi \cdot m_{p} k T}{h^{2}}\right)^{3 / 2} \exp \frac{E_{v}-\mu}{k T}, \\
n_{i}=2\left(\frac{2 \pi \sqrt{m_{n} m_{p}} \cdot k T}{h^{2}}\right)^{3 / 2} \cdot \exp \left(-\frac{E_{g}}{2 k T}\right) \\
=c_{n}(T) \cdot T^{3 / 2} \cdot \exp \left(-\frac{E_{g}}{2 k T}\right),
\end{gathered}
$$

where $m_{n}, m_{p}$ are the effective masses of the free electrons and holes, respectively, $E_{c}, E_{v}, \mu$, and $E_{g}$ are the lower/higher threshold of the conduction/valence band, the electrochemical potential, and the energy gap of the considered semiconductor, respectively, which are also temperature dependent. One finds that expression (3) is symmetrical relative to the permutation $n, \sigma_{n}, E_{t}-E_{i} \leftrightarrow p, \sigma_{p}, E_{i}-E_{t}$, which leads to the DCS possibility to evaluate $\left|E_{t}-E_{i}\right|,\left|\ln \sigma_{n} / \sigma_{p}\right|$, and so forth, but not of the absolute values $E_{t}-E_{i}, \sigma_{n}, \sigma_{p}$, and so forth without additional elements given by other experimental methods.

3.2. The Approximation of the Completely Depleted Zone. Assuming that, in the depletion zone, the electric field sweeps the holes to the $p$-substrate and the electrons to the potential wells, hence (in this region) $n, p \ll n_{i}^{2}$, the temperature dependence of the depletion dark current will be described by the expression [see relations (4) and (5)]

$$
D e_{\text {dep }}^{-}=D e_{0, \mathrm{dep}}^{-} \cdot T^{3 / 2} \cdot \exp \left(-\frac{E_{g}}{2 k T}\right) \cdot \operatorname{sech}\left[\frac{E_{t}-E_{i}}{k T}+d\right],
$$

where the depletion preexponential factor is given by the expression $\left(V_{\text {th }}\right.$ and $N_{t}$ are the thermal velocity and the traps concentration, resp.)

$$
D e_{0, \mathrm{dep}}^{-}=\frac{x_{\mathrm{dep}} A_{\mathrm{pix}} c_{n} \sqrt{\sigma_{p} \sigma_{n}} \cdot V_{\mathrm{th}} N_{t}}{2},
$$

and "the polarization degree" $d$ of the capture cross-sections for electrons and holes, respectively, is

$$
\operatorname{pdg} \equiv d=\arg \tanh \left(\frac{\sigma_{n}-\sigma_{p}}{\sigma_{n}+\sigma_{p}}\right) .
$$

Taking into account the possible concomitant presence of different traps $j$ in each pixel, the previous expression (4) becomes

$$
\begin{aligned}
D e_{\text {dep }}^{-} & =T^{3 / 2} \cdot \exp \left(-\frac{E_{g}}{2 k T}\right) \cdot \sum_{j} D e_{0, \text { dep } . j}^{-} \operatorname{sech}\left[\frac{E_{t j}-E_{i}}{k T}+d_{j}\right] \\
& =D e_{0, \text { dep.eff. }}^{-} \cdot T^{3 / 2} \cdot \exp \left(-\frac{E_{g}}{2 k T}\right) \cdot \operatorname{sech}\left[\frac{E_{t, \text { eff }}-E_{i}}{k T}+d_{\text {eff }}\right],
\end{aligned}
$$

where $D e_{0, \text { dep.eff. }}^{-}, E_{t, \text { eff. }}$, and $d_{\text {eff. }}$ are the effective preexponential factor, trap energy, and polarization degree of $e^{-}, h$ capture cross-sections, corresponding to the considered pixel.

Assuming equal capture cross-sections for holes and electrons, hence a null polarization degree, the expression of the temperature dependence of the depletion dark current, becomes

$$
D e_{\text {dep }}^{-}=D e_{0, \text { dep.eff. }}^{-} \cdot T^{3 / 2} \cdot \exp \left(-\frac{E_{g}}{2 k T}\right) \cdot \operatorname{sech}\left[\frac{E_{t, \text { eff }}-E_{i}}{k T}\right] .
$$

Because the temperature dependence of all physical parameters of the preexponential factor seems to be very weak (in comparison with the exponential dependence of the last 2 factors, especially), we can assume that the temperature dependence of the depletion dark current is due mainly to the last 3 factors of expression (6).

3.3. Choice of the Uniqueness Parameters. Adding the expression of the free-field region (equivalent to the diffusion, for weakly doped semiconductors) dark current [36-38, 83-85], one finds (see also [54]) that the most suitable expression of the temperature dependence of the dark current in CCDs is given by the relation

$$
\begin{aligned}
D e^{-}(T)= & D e_{\text {diff }}^{-}(T)+D e_{\text {dep }}^{-}(T) \\
= & T^{3} \exp \left(\ln D e_{0, \text { diff }}^{-}-\frac{E_{g}}{k T}\right)+T^{3 / 2} \\
& \cdot \exp \left(\ln D e_{0, \text { dep }}^{-}-\frac{E_{g}}{2 k T}\right) \cdot \operatorname{sech}\left[\frac{E_{t}-E_{i}}{k T}+d\right] .
\end{aligned}
$$


The detailed analysis accomplished in the frame of works [52-54] pointed out that the most convenient choice of the uniqueness parameters corresponds to the order (a) $\ln D e_{0, \text { diff }}^{-}, \ln D e_{0, \text { dep }}^{-}$(logarithms of the preexponential factors of the diffusion and depletion current, resp.) and $E_{g}$ (the effective (temperature averaged) energy gap), (b) the difference $E_{t}-E_{i}$ of the energies of the trap and of the intrinsic Fermi level, respectively, or its modulus $\left|E_{t}-E_{i}\right|$ (when the fitting relation (6) is used), and (c) the depolarization degree $d$ of the capture cross-sections of electrons and holes, respectively, given by relation (5).

A synthesis of the main features of the basic versions of the DCS method is presented in Table 1.

The columns of Table 1 point out the (a) basic theoretical relations of the classical McGrath-McColgin DCS method and of our computational DCS approach and (b) the specific advantages of each procedure, related to a global investigation (the classical DCS method) and to the per pixel analysis (our Computational approach).

\section{Study of the Possibilities of Identification of the Impurities and/or Defects Embedded in the Semiconductor Crystalline Lattice}

4.1. Main Characteristic Parameters of the Impurities and/or Defects. The main characteristic parameters of the impurities and/or defects embedded in the forbidden band of a semiconductor are

(a) the capture cross-sections of the free electrons $\sigma_{n}$ and holes $\sigma_{p}$ by the different types of traps or their geometrical average: $\sigma_{\text {ave }} \equiv \sigma=\sqrt{\sigma_{n} \sigma_{p}}$ [28] and the corresponding polarization degree, defined in the frame of this work: pdg $\equiv d=\arg \tanh \left(\left(\sigma_{n}-\sigma_{p}\right) /\left(\sigma_{n}+\right.\right.$ $\left.\left.\sigma_{p}\right)\right)$,

(b) different (and related) generation rates of the charge carriers:

(i) the emission rate, defined by the classical expression of the number of captures (through collisions) in the time unit, in terms of the mean thermal velocity $V_{\text {th }}$ and the considered traps type concentration $n_{t}$ in the volume unit [25]:

$$
e=\frac{\Delta N}{\Delta t}=V_{\mathrm{th}} \cdot \sigma_{\mathrm{em}} \cdot n_{t}=\frac{V_{\mathrm{th}} \cdot \sigma \cdot N_{b}}{g} \cdot \exp \left(-\frac{\Delta E}{k T}\right),
$$

where $N_{b}$ is the effective density of states at the border of the of the respective carriers band, $g$ is the degeneracy of the trap level, while $\Delta E$ is the energy separation (the so-called activation energy) between the trap level and the border of the corresponding carriers band,

(ii) the generation rate given by 1 trap in $a \mathrm{~cm}^{3}$, defined as

$$
r=\frac{e}{n_{t}}=\frac{1}{n_{t}} \cdot \frac{\Delta N}{\Delta t}=V_{\mathrm{th}} \cdot \sigma,
$$

with distinct values for the generation by 1 free electron capture $\left(r_{n}\right)$ or by 1 hole capture $\left(r_{p}\right)$,

(iii) the emission time, defined as

$$
\tau=\frac{1}{e}=\frac{g}{V_{\mathrm{th}} \cdot \sigma \cdot N_{b}} \cdot \exp \left(\frac{\Delta E}{k T}\right),
$$

(c) the energy level, given by its absolute value: $E_{v}+E_{a}$ or $E_{c}-E_{a}$ in terms of the energies corresponding to the upper/lower thresholds of the valence/conduction band and the activation energy, respectively, or by the modulus $\left|E_{t}-E_{i}\right|$ of the distance from the considered trap to the intrinsic Fermi level (taking into account that we have chosen the value $E_{g} \approx 1.08 \mathrm{eV}$ for the effective (averaged on the temperature interval $222 \cdots 291 \mathrm{~K})$ energy gap; we used for Si the value $E_{i} \approx$ $0.54 \mathrm{eV}$ (see also [28])).

4.2. Evaluation of the Polarization Degree of the Capture CrossSections of Free Electrons and Holes, Respectively. As it was found (see, e.g., relation (10)), the polarization degree $d$ of the capture cross-sections of the free electrons and holes, respectively, intervenes in the expression of the depletion dark current, which is prevalent at low temperatures. For this reason, even if the low temperatures dark currents are considerably weaker (hence, their use implies considerably higher errors) than those corresponding to higher temperatures, the evaluation of the polarization degree imposes the use of the dark current for all 8 studied temperatures. Starting from the evaluated values of the logarithms of preexponential factors corresponding to the diffusion In Diff and depletion ln Dep dark current, respectively, as well as from the evaluated effective energy gap $E_{g}$, it is evaluated also the last factor of expression (10):

$$
\text { Fact }=\operatorname{sech}\left[\frac{E_{t, \text { eff. }}-E_{i}}{k T}+d_{\text {eff. }}\right],
$$

for all studied temperatures.

In the following are determined the slope $\left(E_{t}-E_{i}\right) / k$ and the intercept $d$ of the least squares (regression) straight line, $\arg \operatorname{sech}($ Fact $)=F(1 / T)$, and the correlation coefficient corresponding to this regression line.

4.3. Basic Features of the Most Efficient GenerationRecombination Traps. Starting from the expression of the effective generation-recombination life of electrical charge carriers in the depletion region (see, e.g., [28, 36]),

$$
\begin{aligned}
\tau & \stackrel{\Delta}{=} \frac{n_{i}}{2 U}=\frac{x_{\mathrm{dep}} A_{\mathrm{pix}} n_{i}}{2 D e_{\mathrm{dep}}^{-}} \\
& =\frac{\sigma_{n} \exp \left(\left(E_{t}-E_{i}\right) / k T\right)+\sigma_{p} \exp \left(\left(E_{i}-E_{t}\right) / k T\right)}{\sigma_{p} \sigma_{v} V_{\mathrm{th}} N_{t}},
\end{aligned}
$$


TABLE 1: Comparison of the main versions of the classical and computational approach of the dark current spectroscopy (DCS) method.

\begin{tabular}{|c|c|c|c|c|}
\hline $\begin{array}{l}\text { The DCS method } \\
\text { version }\end{array}$ & Input data & Accepted approximations & $\begin{array}{c}\text { Basic } \\
\text { expression(s) }\end{array}$ & $\begin{array}{l}\text { Main evaluated } \\
\text { parameter }\end{array}$ \\
\hline \multirow{4}{*}{$\begin{array}{l}\text { (1) Classical DCS } \\
\text { method (ClDCS) } \\
\text { (a) McGrath et al. } \\
\text { [28] } \\
\text { (b) McColgin et } \\
\text { al. } \\
{[29-32]} \\
\text { (c) Webster et al. } \\
\text { [35] }\end{array}$} & $\begin{array}{c}\text { Histogram: } \\
\text { number of pixels } \\
\text { versus dark current } \\
{[28]}\end{array}$ & $\begin{array}{l}\text { Deep-depletion mode: } n, p \ll n_{i} \\
\text { Equal cross-sections: } \sigma_{n}=\sigma_{p}\end{array}$ & $j_{\text {dark }}=\sqrt{\sigma_{n} \sigma_{p}} \cdot V_{\text {th }} n_{i} n_{t} q W / 2$ & $\begin{array}{l}\text { The average } \\
\text { cross-section } \\
\sigma \equiv \sigma_{\text {ave }}=\sqrt{\sigma_{n} \sigma_{p}}\end{array}$ \\
\hline & $\begin{array}{l}\text { Temperature } \\
\text { dependence of the } \\
\text { dark current [31] }\end{array}$ & $\begin{array}{l}\text { Deep-depletion mode: } n, p \ll n_{i} \\
\qquad\left|E_{t}-E_{i}\right| \lesssim k T\end{array}$ & $j_{d} \propto \exp \left[-\left|E_{t}-E_{i}\right| / k T\right]$ & $\left|E_{t}-E_{i}\right|$ \\
\hline & $\begin{array}{l}\text { Traps concentration } \\
\left(n_{t}\right) \text { and carrier } \\
\text { velocity }\left(V_{\text {th }}\right) \text { from } \\
\text { other methods [30] }\end{array}$ & $\begin{array}{l}\text { Deep-depletion mode: } n, p \ll n_{i} \\
\text { Equal cross-sections: } \sigma_{n}=\sigma_{p}\end{array}$ & $\Delta N_{c} / \Delta t=1 / \tau=V_{\mathrm{th}} \cdot \sigma \cdot n_{t}$ & $\begin{array}{c}\text { The generation } \\
\text { (emission) rate, } \\
e^{-} / s, \\
e \equiv \Delta N_{c} / \Delta t=1 / \tau\end{array}$ \\
\hline & $\begin{array}{c}\text { Temperature } \\
\text { dependence of the } \\
\text { generation (emission) } \\
\text { rate [33] }\end{array}$ & $\begin{array}{l}\text { Validity of the Arrhenius } \\
\text { equation }\end{array}$ & $\Delta N_{c} / \Delta t=1 / \tau \equiv k=A \cdot \exp \left(-E_{a} / k T\right)$ & $\begin{array}{l}\text { The activation energy, } \\
\qquad E_{a}\end{array}$ \\
\hline \multirow{4}{*}{$\begin{array}{l}\text { (2) Computational } \\
\text { DCS approach } \\
\text { (CA-DCS) } \\
\text { (a) Widenhorn et } \\
\text { al. } \\
{[36,37,47-56]} \\
\text { (b) Widenhorn et } \\
\text { al. } \\
\text { [51-56] }\end{array}$} & $\begin{array}{l}\text { Temperature } \\
\text { dependence of the } \\
\text { dark current }[36,37]\end{array}$ & $\begin{array}{l}\quad n, p \ll n_{i}, \sigma_{n}=\sigma_{p} \\
\text { Very deep-level traps: } \\
\qquad\left|E_{t}-E_{i}\right| \ll k T\end{array}$ & $\begin{aligned} j_{d}= & D_{0, \text { diff. }} T^{3} \exp \left(-E_{g} / k T\right) \\
& +D_{0, \text { dep }} T^{3 / 2} \exp \left(-E_{g} / 2 k T\right)\end{aligned}$ & $\begin{array}{l}\text { The preexponential } \\
\text { factors } \\
D_{0, \text { diff.; }} ; D_{0, \text { dep }} \rightarrow n_{t}\end{array}$ \\
\hline & $\begin{array}{l}\text { Idem and Arrhenius } \\
\text { preexponential factor } \\
\text { dependence on the } \\
\text { activation energy } \\
{[36,37,47-51]}\end{array}$ & $\begin{array}{c}\text { The validity of the Arrhenius and } \\
\text { Meyer-Neldel relations }\end{array}$ & $\begin{aligned} j_{d} & =D_{0} \exp (-\Delta E / k T) \\
D_{0} & =D_{00} \exp \left(\Delta E / E_{\mathrm{MN}}\right)\end{aligned}$ & $\begin{array}{l}\text { The Meyer-Neldel } \\
\text { energy } E_{\mathrm{MN}} \text { and the } \\
\text { preexponential factor } \\
D_{00}\end{array}$ \\
\hline & $\begin{array}{l}\text { The temperature } \\
\text { dependence of the } \\
\text { energy gap } E_{g}[36,82]\end{array}$ & $\begin{array}{c}\text { Negligible effect on dark current } \\
\text { of } E_{g}=f(T) \text {, relative to those of } \\
\left|E_{t}-E_{i}\right| \text { and even of } \\
d= \\
\arg \tan h\left(\left(\sigma_{n}-\sigma_{p}\right) /\left(\sigma_{n}+\sigma_{p}\right)\right) \\
\text { and } n, p \ll n_{i}\end{array}$ & $\begin{aligned} j_{d, \mathrm{dep}}= & D_{0, \mathrm{dep}} T^{3 / 2} \exp \left(-E_{g} / 2 k T\right) \\
& \cdot \operatorname{sech}\left[\left(E_{t}-E_{i}\right) / k T+d\right]\end{aligned}$ & $\begin{array}{l}D_{0, \text { diff., }}, D_{0, \text { dep }} \\
E_{g} \text { (effective } \\
\text { parameter), } \\
\left|E_{t}-E_{i}\right|, \text { and } d \\
\quad \rightarrow \sigma_{n}, \sigma_{p}\end{array}$ \\
\hline & $\begin{array}{l}\text { Results concerning } \\
D_{0, \text { diff. }}, D_{0, \text { dep }} \\
E_{g} \text { (effective } \\
\text { parameter), } \\
\left|E_{t}-E_{i}\right|, \text { and } d \\
{[52-54]}\end{array}$ & Idem & $\begin{array}{c}\text { Single or double linear } \\
\text { corelations between some effective } \\
\text { parameters }\end{array}$ & $\begin{array}{c}\text { Correlations } \\
\text { coefficients, } \\
\text { high: } \\
\ln D_{0, \text { diff. }}=f\left(E_{g}\right), \\
\ln D_{0, \text { dep }}= \\
f\left(\left|E_{t}-E_{i}\right|\right), \\
\text { medium values: } \\
\ln D_{0, \text { dep }}=f\left(E_{g}\right), \\
\text { low values: } \\
\ln D_{\text {Arrh }}=f\left(E_{g}\right)\end{array}$ \\
\hline
\end{tabular}

it is very easy to find that this effective generation-recombination life presents a sharp minimum (i.e., a maximum dark current emission) for

$$
0=\frac{d \tau}{d E_{t}}=\frac{1}{\sigma_{p} \sigma_{n} V_{\mathrm{th}} N_{t}}\left[\frac{\sigma_{n}}{k T} \exp \frac{E_{t}-E_{i}}{k T}-\frac{\sigma_{p}}{k T} \exp \frac{E_{i}-E_{t}}{k T}\right],
$$

equivalent to the condition

$$
E_{t}=E_{i}+\frac{k T}{2} \ln \left(\frac{\sigma_{p}}{\sigma_{n}}\right)
$$

Because in the middle of the temperature interval studied by us $(\approx 260 \mathrm{~K})$ we have $(k T / 2) \cong 11.2125 \mathrm{meV}$, it results that (i) $\left|E_{t}-E_{i}\right| /\left(E_{g} / 2\right) \leq 0.2$; hence the most active impurities correspond to a rather deep energy levels (near to the Fermi level; and that is, they correspond to deep-level traps), (ii) $\mid E_{t}-$ $E_{i} \mid /(k T / 2) \cong 0.8 \cdots 5$; it results that the polarization degree of the capture cross-sections of holes and electrons, respectively, has to be rather large (of the magnitude order of 1 ).

Of course, the experimentally found depletion dark current does not correspond exactly to the emission maximum; hence (a) some specific numerical calculations are necessary, but (b) the assumption on the possibility to consider the capture cross-sections of holes and electrons as equal seems to be wrong. 
TABLE 2: Some known values of the traps energy levels, of both capture cross-sections of free electrons and holes, respectively, in silicon, as well as of their polarization degree (pdg), implicitly.

\begin{tabular}{|c|c|c|c|c|c|c|c|c|}
\hline Trap & Group & Energy (eV) & $\sigma_{n}\left(\mathrm{~cm}^{2}\right)$ & $\sigma_{p}\left(\mathrm{~cm}^{2}\right)$ & $k=\sigma_{n} / \sigma_{p}$ & pdg & Reference & $\begin{array}{c}U\left(55^{\circ} \mathrm{C}\right) \\
e^{-/ s}[9]\end{array}$ \\
\hline \multirow{2}{*}{$\mathrm{Au}_{s}^{-}$} & \multirow{2}{*}{11} & $E_{i}-0.01$ & $1.4 \times 10^{-16}$ & $7.6 \times 10^{-15}$ & 0.01842 & -1.997 & {$[86]$} & \\
\hline & & & $5.0 \times 10^{-16}$ & $1.0 \times 10^{-15} \propto T^{-4}$ & 0.5 & -0.3466 & {$[87]$} & 565 \\
\hline $\mathrm{MnB}$ & $7 ; 13$ & $E_{i}-0.01$ & $9.0 \times 10^{-14}$ & & & & {$[88]$} & \\
\hline$\left(\mathrm{Mn}_{i}^{+} \mathrm{B}_{s}^{-}\right)^{+}$ & $7 ; 13$ & $E_{i}+0.01$ & $2.1 \times 10^{-12}$ & $3.5 \times 10^{-13}$ & 6.0 & +1.282 & [89] & \\
\hline $\begin{array}{l}\mathrm{Co}_{i}^{+} \\
\mathrm{Ni}_{i}^{+}\end{array}$ & $\begin{array}{c}9 \\
10\end{array}$ & $E_{i}-0.02$ & & $\sigma=\left(\sigma_{n} \cdot \sigma_{p}\right)^{1 / 2}=$ & $6.6 \times 10^{-15}$ & & {$[90]$} & 3700 \\
\hline $\mathrm{Pt}_{i}^{-}$ & 10 & $E_{i}+0.02$ & $4.5 \times 10^{-15}$ & $1.09 \times 10^{-14}$ & 2.42 & +0.442 & {$[91]$} & 970 \\
\hline CrAl & $6 ; 13$ & $E_{i}-0.048$ & & $1.5 \times 10^{-16}$ & & & {$[88]$} & \\
\hline $\mathrm{CrGa}$ & $6 ; 13$ & $E_{i}-0.058$ & & $1.5 \times 10^{-15}$ & & & {$[88]$} & \\
\hline $\mathrm{Zn}_{s}^{--}$ & 12 & $E_{i}+0.07$ & $1.3 \times 10^{-19}$ & $6.6 \times 10^{-15}$ & $1.97 \times 10^{-5}$ & -5.417 & {$[86]$} & \\
\hline $\mathrm{MnAl}$ & $7 ; 13$ & $E_{i}+0.09$ & $5.0 \times 10^{-15}$ & & & & {$[88]$} & \\
\hline $\mathrm{Mn}_{i}^{+}$ & 7 & $E_{i}+0.09$ & & & 9.4 & +1.1204 & {$[89]$} & \\
\hline \multirow{2}{*}{$\begin{array}{l}\mathrm{PVp}^{-} \equiv \\
\text { E-center }\end{array}$} & \multirow{2}{*}{14} & $E_{i}+0.10$ & \multirow{2}{*}{\multicolumn{3}{|c|}{$\sigma=\left(\sigma_{n} \cdot \sigma_{p}\right)^{1 / 2} \approx 6.6 \times 10^{-15}$}} & & {$[92]$} & 70 \\
\hline & & $E_{i}+0.084$ & & & & \multicolumn{3}{|c|}{$[92]$} \\
\hline $\mathrm{VV} e^{-}$trap & 14 & $E_{i}+0.15$ & $4.0 \times 10^{-15}$ & & & & [1, page 820$]$ & \\
\hline $\mathrm{Fe}_{i}^{+}$ & 8 & $E_{i}-0.16$ & $5.0 \times 10^{-14}$ & $7.0 \times 10^{-17}$ & 714.3 & +3.286 & {$[86]$} & \\
\hline $\mathrm{V}_{i}^{++}$ & 5 & $E_{i}-0.18$ & $5.0 \times 10^{-14}$ & $3.0 \times 10^{-18}$ & 16667 & +4.86 & {$[86]$} & \\
\hline $\mathrm{Pt}_{s}^{+}$ & 10 & $E_{i}-0.18$ & & $5.4 \times 10^{-14}$ & & & {$[91]$} & \\
\hline $\mathrm{Zn}_{s}^{-}$ & 12 & $E_{i}-0.21$ & $1.5 \times 10^{-15}$ & $4.4 \times 10^{-15}$ & 0.3409 & -0.538 & {$[86]$} & \\
\hline $\mathrm{Mn}_{i}^{++}$ & 7 & $E_{i}-0.21$ & & & $23.1(18.5 \div 28.3)$ & +1.57 & {$[89]$} & \\
\hline \multirow{2}{*}{$\mathrm{Mo}_{i}^{+}$} & \multirow{2}{*}{6} & $E_{i}-0.26$ & $1.6 \times 10^{-14}$ & $6.0 \times 10^{-16}$ & 26.67 & +1.642 & {$[93]$} & \\
\hline & & $E_{i}-0.223$ & $7.8 \times 10^{-15}$ & $6.0 \times 10^{-16}$ & 13 & +1.282 & [93] & \\
\hline$\left(\mathrm{Cr}_{i}^{+} \mathrm{B}_{s}^{-}\right)^{-}$ & $6 ; 13$ & $E_{i}-0.26$ & $5.0 \times 10^{-15}$ & $1.0 \times 10^{-14}$ & 0.5 & -0.3466 & {$[94]$} & \\
\hline $\mathrm{PV}^{+}$ & 14 & $E_{i}-0.27$ & & & & & {$[92]$} & 1.8 \\
\hline $\mathrm{Ti}_{i}^{+}$ & 4 & $E_{i}+0.27$ & $3.1 \times 10^{-14}$ & $1.4 \times 10^{-15}$ & 22.14 & +1.549 & {$[86]$} & \\
\hline $\mathrm{Ti}_{i}^{++}$ & 4 & $E_{i}-0.28$ & $1.3 \times 10^{-14}$ & $2.8 \times 10^{-17}$ & 464.3 & +3.070 & {$[86]$} & \\
\hline$\left(\mathrm{Fe}_{i}^{+} \mathrm{B}_{s}^{-}\right)^{+}$ & $8 ; 13$ & $\begin{array}{c}E_{i}+0.28 \\
( \pm 0.02)\end{array}$ & $\begin{array}{c}1.4 \times 10^{-14} \\
( \pm 0.02)\end{array}$ & $\begin{array}{l}1.1 \times 10^{-15} \\
(0.5 \div 2.5)\end{array}$ & 13 & +1.282 & {$[90]$} & \\
\hline $\mathrm{MnAu}$ & $7 ; 11$ & $E_{i}+0.30$ & & & & & & \\
\hline $\mathrm{Pt}_{s}^{+}$ & 10 & $E_{i}+0.31$ & $3.4 \times 10^{-15}$ & & & & {$[91]$} & \\
\hline \multirow{2}{*}{$\mathrm{Cr}_{i}^{++}$} & \multirow{2}{*}{6} & $E_{i}+0.32$ & $2.3 \times 10^{-13}$ & $1.1 \times 10^{-13}$ & 2.091 & +0.369 & {$[86]$} & \\
\hline & & $E_{i}+0.30$ & $2.0 \times 10^{-14}$ & $4.0 \times 10^{-15}$ & 5 & +0.805 & {$[94]$} & \\
\hline $\begin{array}{l}\text { VV hole } \\
\text { trap }\end{array}$ & 14 & $E_{i}-0.33$ & & $2.0 \times 10^{-16}$ & & & [1, page 820] & \\
\hline $\begin{array}{l}\mathrm{OV}^{-} \equiv \\
\text { A-center }\end{array}$ & 16 & $E_{i}+0.37$ & $1.0 \times 10^{-14}$ & & & & {$[1$, page 820$]$} & \\
\hline $\begin{array}{l}\text { all Mn } \\
\text { Traps }\end{array}$ & 7 & & $\sigma=\left(\sigma_{\min } \cdot c\right.$ & $2 \approx 1.0 \times 10^{-15} ; \sigma_{\mathrm{r}}$ & $/ \sigma_{\min } \sim 10^{6}$ & & {$[32,89]$} & 6400 \\
\hline
\end{tabular}

TABLE 3: Analysis of the physical meaning of the possible signs of the slope and intercept of the regression line (15).

\begin{tabular}{lcccc}
\hline Sign of the slope $s$ & Sign of the intercept $i$ & sc & Value of $\left|E_{t}-E_{i}\right|$ & Value of $|\mathrm{pdg}|$ \\
\hline$>0$ & $>0$ & +1 & $s$ & $i$ \\
$>0$ & $<0$ & -1 & $-\mathrm{sc} \cdot s=+s$ & $\mathrm{sc} \cdot i=-i$ \\
$<0$ & $>0$ & -1 & $\mathrm{sc} \cdot s=-s$ & $-\mathrm{sc} \cdot i=+i$ \\
\hline
\end{tabular}




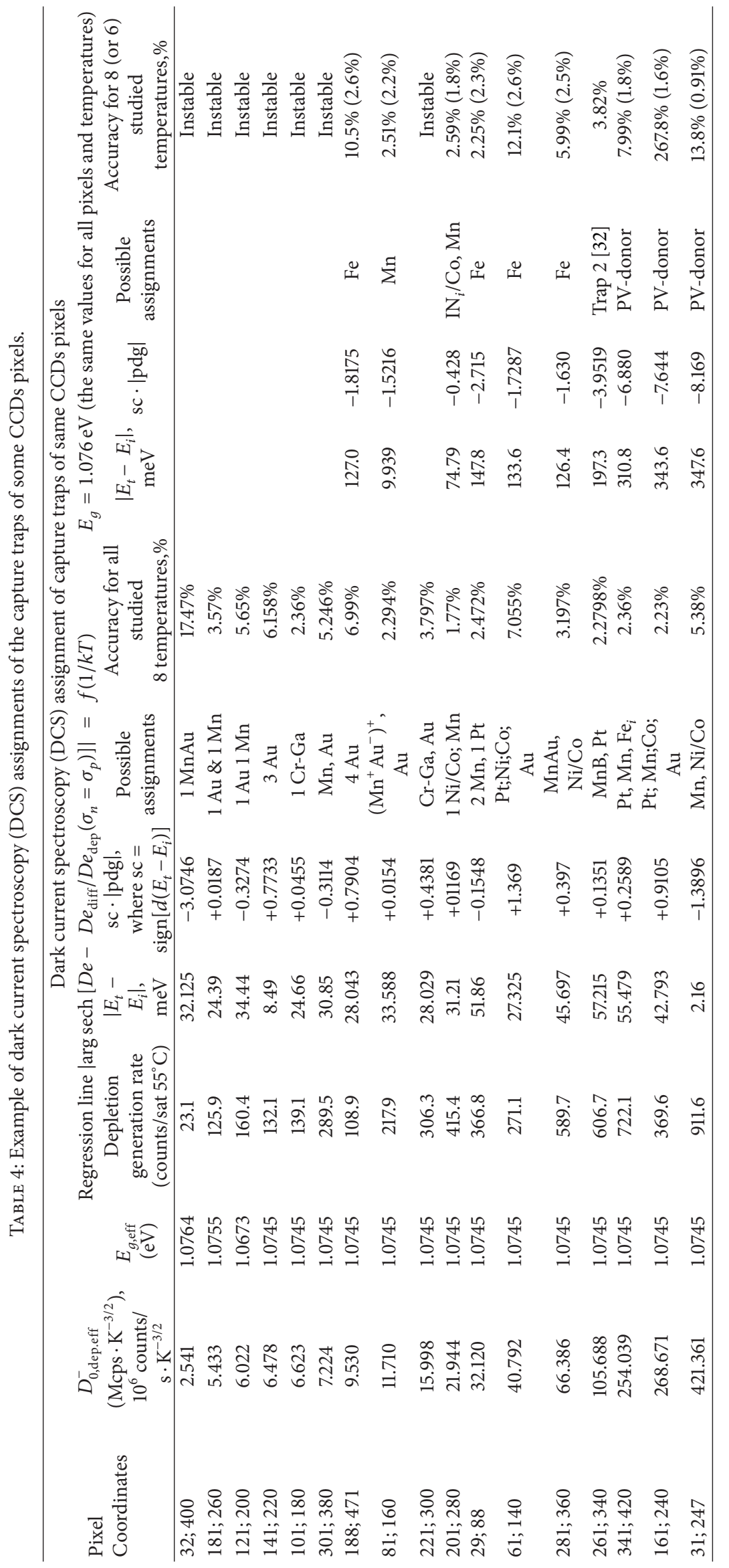




\section{Interpretation of the Found Numerical Results}

The main difficulties of our study correspond to the

(i) possible presence in each pixel of several types of traps and/or impurities, which means that the obtained values are in fact averages over the present traps/impurities,

(ii) complexity of the used SRH theoretical model, which determines an effective character of all evaluated uniqueness parameters.

5.1. Assignment Criteria of the Individual Capture Traps from Semiconductors. The basic assignment criteria of the individual capture traps due to contaminants, to the defects produced by high-energy radiation particles, or to some combinations of these basic traps (as the E-centers, Acenters, etc.) are (a) the trap energy level, expressed by means of the activation energy as (i) $E_{c}-E_{a}$ and (ii) $E_{v}+E_{a}$, or by means of the intrinsic Fermi level energy as $E_{i} \pm\left|E_{t}-E_{i}\right|$, (b) the capture cross-sections of the free electrons $\sigma_{n}$ or holes $\sigma_{p}$, respectively, or by the geometrical average of cross-sections $\sigma=\sqrt{\sigma_{n} \sigma_{p}}[28]$ and the polarization degree of capture crosssections $d=\arg \tanh \left(\left(\sigma_{n}-\sigma_{p}\right) /\left(\sigma_{n}+\sigma_{p}\right)\right)$, defined by this work, and (c) the generation-recombination rate by means of depletion processes $[28,36]$ and relation (2) and the depletion preexponential factor $\left(4^{\prime}\right),\left(5^{\prime}\right)$. In order to achieve such assignments of the traps states detected by the main present experimental methods, Table 2 presents the synthesis of the specialty literature results concerning the states whose basic features specified above were already measured.

Relative to the atoms and/or ions involved in Table 2, we have to mention (a) several of these nanoparticles were present in the experimental data of some previous works (e.g., [52]) and (b) according to our knowledge, the present work is the first one to accomplish a wide-scale analysis of free electrons and holes, respectively, capture cross-sections, this finding justifying the involvement of some elements rarely met in CCDs, which will allow us the obtainment in following of some new results.

The analysis of the experimental data synthesized by Table 2 points out the possibility to classify the different capture traps states in terms of the newly defined here state character (symbol sc), defined as

$$
\mathrm{sc}=\operatorname{sign}\left[\mathrm{pdg} \cdot\left(E_{t}-E_{i}\right)\right] .
$$

From Table 2 one finds that while for the so-called "normal" states (as those of $\mathrm{Ti}_{i}^{+}, \mathrm{Cr}_{i}^{+},\left(\mathrm{Cr}_{i}^{+} \mathrm{B}_{s}^{-}\right)^{-}, \mathrm{Mn}_{i}^{+},\left(\mathrm{Mn}_{i}^{+} \mathrm{B}_{s}^{-}\right)^{-}$, $\left.\left(\mathrm{Fe}_{i}^{+} \mathrm{B}_{s}^{-}\right)^{-}, \mathrm{Au}_{s}^{-}, \mathrm{Zn}_{s}^{-}, \mathrm{Pt}_{i}^{+}\right)$the state character has the value $\mathrm{sc}=+1$, for the "trans-Fermi level acceptor/donor states" $\left(\mathrm{Ti}_{i}^{++}, \mathrm{V}_{i}^{++}, \mathrm{Mo}_{i}^{+}, \mathrm{Mn}_{i}^{++}, \mathrm{Fe}_{i}^{+}, \mathrm{Zn}_{s}^{--}\right)$it has the value sc $=-1$. This finding will be useful for the identification of the capture traps states in the case of small groups of traps inside some CCDs pixels.

5.2. DCS Assignment Criteria for the Small Groups of Capture Traps of Some CCD Pixels. As an example of application of the dark current spectroscopy (DCS) assignment criteria for certain small groups of capture traps of some CCDs, we studied the dark currents of 20 randomly chosen pixels of a $512 \times 512$ SI003AB thinned CCD chip of a backside illuminated Spectra Video camera manufactured by PixelVision, Beaverton (Oregon, USA), the corresponding numerical data being kindly indicated to us by Professors Erik Bodegom and Ralf Widenhorn, from Portland State University (Oregon) [52]. The average number of traps/pixel was of about 10 [36]; hence we studied both some pixels with very small numbers of pixels and other pixels with some tens of such capture traps.

Excepting the pixels with the smallest dark currents and implicitly the smallest values of the depletion dark current preexponential factor $D e_{0 \text {,dep.eff. }}^{-}$where the evaluated physical parameters could correspond to some individual capture traps, for the larger values of $D e_{0 \text {,dep.eff. }}^{-}$these values represent some rather intricate (see relation $\left(5^{\prime}\right)$ ) averages over 2 or more capture traps, being so effective parameters.

Being the complex character of semiconductors (the temperature dependence of their basic parameters, of the energy gap $E_{g}$, particularly), the experimental data processing can be accomplished in 2 versions assuming (a) an effective (specific to the experimental data obtained for each pixel) energy gap $E_{g, \text { eff. }}$ or (b) a constant value for all temperatures, common for all pixels, for example $E_{g} \approx 1.076 \mathrm{eV}$.

After the evaluation of the diffusion $D e_{0 \text {,diff. }}^{-}$and depletion $D e_{0, \text { dep. }}^{-}$preexponential factors and of the effective value of the energy gap $E_{g \text {,eff. }}$, concomitantly with a zero-order approximation of the modulus of the of the average value (for all traps of the considered CCD pixel) difference $\left|E_{t}-E_{i}\right|$ of energies of the CCDs traps and of the intrinsic Fermi level, it becomes possible to evaluate the factor $\operatorname{sech}\left(\left(\left(E_{t}-\right.\right.\right.$ $\left.\left.E_{i}\right)(k T)+d\right)($ see relation $(7))$ for all 8 studied temperatures: $222,232,242,252,262,271,281$, and $291 \mathrm{~K}$ [52]. Given that the argument of the hyperbolic secant function is an even function, we will study the least squares fit (regression line) for the linear dependence

$$
\left|\frac{E_{t}-E_{i}}{k T}+d\right|=f\left(\frac{1}{k T}\right) .
$$

One finds that using the DCS method, it is possible to evaluate only the $\left|E_{t}-E_{i}\right|$ and $|d| \equiv \mid$ pdg|. Depending on the signs of the slope $s$ and intercept $i$ of the regression line (15), it is possible to establish the value of the state character sc, as it is shown in Table 3.

One finds that the general relation between the intercept $i$ of the least-squares (regression) line (15) and the modulus of the polarization degree pdg of the capture cross-sections is

$$
i=\mathrm{sc} \cdot|\mathrm{pdg}| \text {. }
$$

The priority order of the dark current spectroscopy (DCS) assignment criteria of the capture traps of a CCD pixel refers mainly to the values of the (a) preexponential factor $D e_{0, \text { dep.eff. }}^{-}$of the depletion dark current, which can indicate the magnitude order of the number of traps inside the considered CCD pixel, (b) the modulus of the energies difference $\left|E_{t}-E_{i}\right|$, (c) the capture cross-sections of different traps, 
(d) the state character sc, and (e) the generation rate $U$. Of course, the traps states with the smallest values of $D e_{0 \text {,dep.eff. }}^{-}$ correspond to the lowest numbers of traps. As it results from Table 4, from the studied CCD pixels, that of coordinates 321, 400 seems to have the lowest traps population, maybe only one trap. Given that the corresponding depletion dark current is very weak, the corresponding measurement errors are very large, and the trap assignment is rather difficult. As it results from the study of the specialty literature $[86,89,90,95]$, the main "candidates" for this pixel trap are mainly the electronic states of Au and Mn. But, as it results from Table 2, while the electronic states of Au are usually "normal" ones $(\mathrm{sc}=+1)$, some of the numerous electronic states of $\mathrm{Mn}$ can belong also to the trans-Fermi capture states (i.e., $s c=+1$, e.g., the electronic state $\left.\mathrm{Mn}_{i}^{++}\right)$. Given that the electronic state of the MnAu nanocomplex presents the value $\left|E_{t}-E_{i}\right|=0.30 \mathrm{eV}$, we consider this complex and its atoms $\mathrm{Mn}$ and $\mathrm{Au}$ as the most justified to correspond to the first 3 pixels from Table 4 (with the lowest value of the depletion preexponential factor).

The analysis of the results synthesized by Table 4 points out also that the strong nonlinearity of the SRH model relations (2) and (7), as well as of the temperature dependence of the semiconductors energy gaps $E_{g}$ (see, e.g., $[36,82]$, etc.), imposes the use of the effective parameter $E_{g, \text { eff. }}$ (pixel) depending on all DCS physical results referring to a given CCD pixel, for of a certain set of studied temperatures. One finds (last columns of Table 4) that the use of a same energy gap $E_{g}$ for all studied pixels leads to results of very low physical plausibility.

\section{Conclusions}

Using some newly defined physical parameters, as the "polarization degree of the capture cross-sections" pdg $\equiv d=$ $\arg \tanh \left(\left(\sigma_{n}-\sigma_{p}\right) /\left(\sigma_{n}+\sigma_{p}\right)\right)$ and the corresponding trap state character sc $=\operatorname{sign}\left[\mathrm{pdg} \cdot\left(E_{t}-E_{i}\right)\right]$, the new physical notion of "trans-Fermi level traps donor/acceptor states," as well as the generalization given by relation $\left(5^{\prime}\right)$ of the McGrath assigning method [28] of the semiconductor traps, our improved DCS method succeeded to provide some predictions about the capture traps induced in semiconductors by nuclear radiations, contamination, and so forth.

The limits of the computational approach of the DCS method were also emphasized:

(a) its insensitivity for the not very-deep traps $\left(\left|E_{t}-E_{i}\right| \gg\right.$ $k T)$,

(b) the impossibility to determine the signs of parameters $E_{t}-E_{i}$ and pdg $=\arg \operatorname{th}\left(\left(\sigma_{h}-\sigma_{n}\right) /\left(\sigma_{h}+\sigma_{n}\right)\right)$.

In order to achieve the assignments of the obtained values of uniqueness parameters to some defects or nanoimpurities intervening in the frame of the studied pixels, a comparison of the most important experimental methods intended to the characterization of these impurities/defects was accomplished. Some additional applications could be obtained by combining the new procedures indicated here with the old one, involving some intentionally (and hence, well-known) introduced impurities. There were pointed out both the important differences between the basic notions and parameters of the dark current spectroscopy method (DCS) and of the deep-level transient spectroscopy (the most important present alternative experimental method) one the possibilities to combine their results.

\section{Acknowledgments}

The authors thank very much Professors Erik Bodegom and Ralf Widenhorn from the Physics Department of the Portland State University for the important awarded information and suggestions, as well as the leadership of the Portland State University (Oregon, USA) for the Memorandum of Understanding 9908/March 6, 2006-2011, with University "Politehnica" from Bucharest, which allowed this cooperation.

\section{References}

[1] J. R. Janesick, Scientific Charge-Coupled Devices, SPIE Press, Bellingham, Wash, USA, 2000.

[2] R. Widenhorn, Charge Coupled Devices, VDM, Saarbruecken, Germany, 2008.

[3] J. B. Spratt, B. C. Passenheim, and R. E. Leadon, "The effects of nuclear radiation on $p$-channel CCD imagers," in Radiation Effects Data Workshop, pp. 116-121, IEEE, 1997.

[4] P. N. K. Deenapanray, W. E. Meyer, and F. D. Auret, "Electricfield enhanced emission and annealing behavior of electron traps introduced in $n$-Si by low energy He ion bombardment," Semiconductor Science and Technology, vol. 14, pp. 41-47, 1999.

[5] S. A. Goodman, F. D. Auret, and W. E. Meyer, "Deep level defects introduced in $n$-GaN by $5.4 \mathrm{MeV} \mathrm{He-ions,"} \mathrm{in} \mathrm{24th} \mathrm{International}$ Conference on the Physics of Semiconductors, D. Gershoni, Ed., World Scientific, Singapore, 1998.

[6] S. Goodman, F. D. Auret, F. K. Koschnick et al., "Field enhanced emission rate and electronic properties of a defect induced in $n$-GaN by $5.4 \mathrm{MeV} H e$-ions," Applied Physics Letters, vol. 74, pp. 809-811, 1999.

[7] H. H. Woodbury and G. W. Ludwig, "Spin resonance of transition metals in silicon," Physical Review, vol. 117, pp. 102-108, 1960.

[8] G. W. Ludwig and H. H. Woodbury, "Spin resonance of Pd and Pt in silicon," Physical Review, vol. 126, pp. 466-470, 1962.

[9] G. W. Ludwig and H. H. Woodbury, "Electron spin resonance in semiconductors," Solid State Physics, vol. 13, pp. 223-304, 1962.

[10] A. A. Bergh and P. J. Dean, "Light-emitting diodes," Proceedings of the IEEE, vol. 60, pp. 156-223, 1972.

[11] H. Carchano and C. Jund, "Electrical properties of silicon doped with platinum," Solid State Electronics, vol. 13, no. 1, pp. 83-90, 1970.

[12] M. Conti and A. Panchieri, "Electrical properties of platinum in silicon," Alta Frequenza, vol. 40, pp. 544-546, 1971.

[13] E. Ohta and M. Sakata, "Thermal emission rates and capture cross sections of majority carriers at vanadium centers in silicon," Solid-State Electron, vol. 23, pp. 759-764, 1980.

[14] T. Kunio, T. Nishino, E. Ohta, and M. Sakata, "Energy levels and degeneracy ratios for chromium in silicon," Solid State Electronics, vol. 24, no. 12, pp. 1087-1091, 1981. 
[15] D. L. Losee, "Admittance spectroscopy of deep impurity levels: ZnTe Schottky barriers," Applied Physics Letters, vol. 21, article 54, 3 pages, 1972.

[16] J. C. Carballes, J. Varon, and T. Ceva, "Capacitives methods of determination of the energy distribution of electron traps in semiconductors," Solid State Communications, vol. 9, pp. 16271631, 1971.

[17] C. T. Sah, W. W. Chen, H. S. Fu, and J. W. Walker, "Thermally stimulated capacitance (TSCAP) in $p$ - $n$ Junctions," Applied Physics Letters, vol. 20, article 193, 3 pages, 1972.

[18] M. G. Buhler, "Impurity centers in $P N$ junctions determined from shifts in the thermally stimulated current and capacitance response with heating rate," Solid-State Electron, vol. 15, pp. 6979, 1972.

[19] C. T. Sah and J. W. Walker, "Thermally stimulated capacitance for shallow majority-carrier traps in the edge region of semiconductor junctions," Applied Physics Letters, vol. 22, article 384, 2 pages, 1973.

[20] C. S. Fuller and J. A. Ditzenberger, "Diffusion of donor and acceptor elements in silicon," Journal of Applied Physics, vol. 27, article 544, 10 pages, 1956.

[21] N. Bendik, Fizika Tverdogo Tela, vol. 12, p. 190, 1970.

[22] N. Bendik, Soviet Physics, Solid state, vol. 12, p. 150, 1970.

[23] C. T. Sah, L. Forbes, L. L. Rosier, and A. F. Tasch Jr., “Thermal and optical emission and capture rates and cross sections of electrons and holes at imperfection centers in semiconductors from photo and dark junction current and capacitance experiments," Solid State Electronics, vol. 13, no. 6, pp. 759-788, 1970.

[24] H. Kukimoto, C. H. Henry, and F. R. Merritt, "Photocapacitance studies of the oxygen donor in $\mathrm{GaP}-\mathrm{I}$. Optical cross sections, energy levels, and concentration," Physical Review B, vol. 7, pp. 2486-2499, 1973.

[25] D. V. Lang, "Deep-level transient spectroscopy, a new method to characterize traps in semiconductors," Journal of Applied Physics, vol. 45, no. 7, pp. 3023-3032, 1974.

[26] A. O. Evwarage and E. Sun, "Electrical properties of platinum in silicon as determined by deep-level transient spectroscopy," Journal of Applied Physics, vol. 47, article 3172, 5 pages, 1976.

[27] Y. K. Kwon, T. Ishikawa, and H. Kuwano, "Properties of Pt-associated deep levels in silicon," Journal of Applied Physics, vol. 61, no. 3, pp. 1058-1055, 1987.

[28] R. D. McGrath, J. Doty, G. Lupino, G. Ricker, and J. Vallerga, "Counting of deep-level traps using a charge-coupled device," IEEE Transactions on Electron Devices, vol. 34, no. 12, pp. 25552557, 1987.

[29] W. C. McColgin, J. P. Lavine, J. Kyan, D. N. Nichols, J. B. Russell, and C. V. Stancampiano, "Effects of deliberate metal contamination on CCD imagers," in Proceedings of the Materials Research Society Symposium, vol. 262, pp. 769-774, Pittsburgh, Pa, USA, 1992.

[30] W. C. McColgin, J. P. Lavine, J. Kyan, D. N. Nichols, and C. V. Stancampiano, "Dark current quantization in CCD image sensors," in Proceedings of the International Electron Devices Meeting, Technical Digest (IEDM '92), pp. 113-116, Rochester, NY, USA, 1992.

[31] W. C. McColgin, J. P. Lavine, and C. V. Stancampiano, "Probing metal defects in CCD image sensors," in Proceedings of the Materials Research Society Symposium, vol. 378, pp. 713-724, Pittsburgh, Pa, USA, 1995.

[32] W. C. McColgin, J. P. Lavine, C. V. Stancampiano, and J. B. Russell, "Deep-level traps in CCD image sensors," in Proceedings of the Materials Research Society Symposium, vol. 510, pp. 475480, 1998.

[33] V. Ninulescu and P. Sterian, "Control of photocurrent in semiconductors through femtosecond pulses," in Proceedings of SPIE, vol. 4430, pp. 722-728, 2001.

[34] R. Rogojan, P. Sterian, and A. R. Sterian, "Spectral behavior and nonlinear optical properties of alumino-phosphate semiconductor," Laser Physics and Applications, vol. 4397, pp. 358-361, 2001.

[35] E. A. G. Webster, R. Nicol, L. Grant, and D. Renshaw, "Validated dark current spectroscopy in a per-pixel basis in CMOS image sensors," in Proceedings of the International Image Sensor Workshop (IISW '09), Bergen, Norway, 2009.

[36] R. Widenhorn, M. M. Blouke, A. Weber, A. Rest, and E. Bodegom, "Temperature dependence of dark current in a CCD," in Proceedings of SPIE, vol. 4669, p. 193, 2002.

[37] E. Bodegom, R. Widenhorn, D. A. Iordache, and V. Iordache, "Numerical analysis of experimental data concerning the temperature dependence of dark current in CCDs," in Proceedings of the 28th Annual Congress of American-Romanian Academy of Arts and Sciences, vol. 2, p. 763, Polytechnic International Press, Montréal, Canada, 2003.

[38] I. Hartwig, R. Widenhorn, and E. Bodegom, "Nonlinearities of the dark current in CCDs," Proceedings of Oregon Science Academy, vol. 42, p. 54, 2006.

[39] "Semiconductors. Sub-volume A2: Impurities and defects in group IV elements, IV-VI and III-V compounds," in Group IV Elements, M. Schulz, Ed., p. 170, Landolt-Börnstein, Springer, Berlin, Germany, 2002.

[40] M. K. Bakhadyrkhanov, G. K. Mavlonov, and S. B. Isamov, "Transport properties of silicon doped with manganese via lowtemperature diffusion," Neorganiche Materialy, vol. 47, no. 5, pp. 545-550, 2011.

[41] M. K. Bakhadyrkhanov, G. K. Mavlonov, and S. B. Isamov, "Transport properties of silicon doped with manganese via lowtemperature diffusion," Inorganic Materials, vol. 47, no. 5, pp. 479-483, 2011.

[42] H. Tada, J. Carter, B. Anspaugh, and R. Downing, Solar Cell Radiation Handbook, JPL Publication, 1982.

[43] R. H. Hopkins, R. G. Seidensticker, and J. R. Davies, Journal of Crystal Growth, vol. 42, p. 493, 1977.

[44] A. Rohatgi, J. R. Davies, and R. H. Hopkins, "Effect of titanium copper and iron on silicon solar cells," Journal of Solid State Electronics, vol. 23, pp. 415-422, 1980.

[45] J. R. Davis, A. Rohatgi, R. H. Hopkins et al., "Impurities in silicon solar cells," IEEE Transactions on Electron Devices, vol. 27, no. 4, pp. 677-687, 1980.

[46] T. Kirchartz, B. E. Pieters, J. Kirkpatrick, U. Rau, and J. Nelson, "Recombination via tail states in polythiophene: fullerene solar cells," Physical Review B, vol. 83, Article ID 115209, 2011.

[47] A. Weber, R. Widenhorn, and E. Bodegom, "Activation energies for dark current in a CCD," Proceedings of Oregon Academy of Science, vol. 38, p. 49, 2002.

[48] R. Widenhorn, M. M. Blouke, A. Weber, A. Rest, and E. Bodegom, "Analysis of the activation energy of dark current in CCD pixels," in Proceedings of IEEE Workshop on CCDs and Advanced Image Sensors, Schloss Elmau, Germany, 2003.

[49] R. Widenhorn, L. Mündermann, A. Rest, and E. Bodegom, "Meyer-Neldel rule for dark current in CCDs," Journal of Applied Physics, vol. 89, article 8179, 4 pages, 2001. 
[50] R. Widenhorn, A. Rest, and E. Bodegom, "The Meyer-Neldel rule for a property determined by two transport mechanisms," Journal of Applied Physics, vol. 91, article 6524, 2002.

[51] E. Bodegom, R. Widenhorn, and D. A. Iordache, "New MeyerNeldel relations for the depletion and diffusion dark currents in some CCDs," in Proceedings of the Internatational Semiconductor Conference (CAS '04), pp. 363-366, Sinaia, Romania, 2004.

[52] R. Widenhorn, E. Bodegom, D. Iordache, and I. Tunaru, "Computational approach to dark current spectroscopy in CCDs as complex systems-I. Experimental part and choice of the uniqueness parameters," Scientific Bulletin-University Politehnica of Bucharest, vol. 72, no. 4, pp. 197-208.

[53] I. Tunaru, R. Widenhorn, D. Iordache, and E. Bodegom, "Computational approach to dark current spectroscopy in CCDs as complex systems-II. Numerical analysis of the uniqueness parameters evaluation," Scientific Bulletin-University Politehnica of Bucharest, vol. 73, no. 1, pp. 149-162, 2011.

[54] E. Bodegom, R. Widenhorn, D. A. Iordache, and I. Tunaru, "Study of some additional possibilities and of the evaluation limits of the dark current spectroscopy (DCS) method," Annals of the Academy of Romanian Scientists, Series on Science and Technology of Information, vol. 4, no. 1, pp. 23-42, 2011.

[55] R. Widenhorn, E. Bodegom, D. Iordache, and V. Iancu, "Study of the temperature dependence of the dark currents nonuniformity for some video-camera chips," in Proceedings of the 32nd International Semiconductor Conference (CAS '09), vol. 2, pp. 463-466, Sinaia, Romania, 2009.

[56] R. Widenhorn, I. Tunaru, E. Bodegom, and D. Iordache, "Study of the numerical modeling of the temperature dependence of the dark current in CCDs," Annals of the Academy of Romanian Scientists, vol. 3, no. 2, pp. 111-122, 2010.

[57] E. Weber and H. G. Riotte, "Iron as a thermal defect in silicon," Applied Physics Letters, vol. 33, article 433, 3 pages, 1978.

[58] E. Weber and H. G. Riotte, "The solution of iron in silicon," Journal of Applied Physics, vol. 51, article 1484, 1980.

[59] N. Wiehl, V. Herpers, and E. Weber, "Solid solutions of transition metals in high purity silicon studied by instrumental neutron activation analysis (INAA) and electron paramagnetic resonance (EPR)," in Proceedings of the Europhysics Conference, Nuclear Physics 7th Divisional Conference on Nuclear Physics Methods in Materials Research, K. Bethge, H. Baumann, H. Jex, and F. Rauch, Eds., pp. 334-336, Vieweg, Braunschweig, Germany, 1980.

[60] N. Wiehl, V. Herpers, and E. Weber, "Study on the solid solubility of transition metals in high-purity silicon by instrumental neutron activation analysis and anticompton-spectrometry," Journal of Radioanalytical Chemistry, vol. 72, pp. 69-72, 1982.

[61] H. G. Riotte, V. Herpers, and E. Weber, Radiochimica Acta, vol. 27, p. 1560, 1986.

[62] J. D. Struthers, "Solubility and diffusivity of gold, iron, and copper in silicon," Journal of Applied Physics, vol. 27, article 1560, 1956.

[63] R. N. Hall and J. H. Racette, "Diffusion and solubility of copper in extrinsic and intrinsic germanium, silicon, and gallium arsenide," Journal of Applied Physics, vol. 35, article 379, 19 pages, 1964.

[64] H. J. Mayer, R. Mehrer, and K. Maier, Radiation Effects in Semiconductors, Conference Series 31, edited by N. B. Urli and J. W. Corbett, Institute of Physics Bristol, London, UK, 1977.

[65] M. K. Bakhadrykhanov, Soviet physics, Solid State, vol. 12, p. 144, 1970.
[66] M. K. Bakhadrykhanov, Soviet Physics: Semiconductors, vol. 4, p. 739, 1970.

[67] A. N. Larsen and A. Mesli, "The hidden secrets of the E-center on Si and Ge," Physica B, vol. 401-402, pp. 85-90, 2007.

[68] L. C. Kimerling, "Defect states in electron-bombarded Si: capacitance transient analysis," in Radiation Effects in Semiconductors, N. B. Urli and J. W. Corbett, Eds., Conference Series 31, p. 221, Institute of Physics Bristol, London, UK, 1977.

[69] H. Lemke, "Eigensehaften der dotierungsniveaus von mangan und vanadium in silizium," Physica Status Solidi A, vol. 64, pp. 549-556, 1981.

[70] H. Lemke, "Eigenschaften einiger störstellenkomplexe von gold in silizium," Physica Status Solidi A, vol. 75, pp. 473-482, 1983.

[71] H. Lemke, "Energieniveaus und bindungsenergien von ionenpaaren in silizium," Physica Status Solidi A, vol. 76, pp. 223-234, 1983.

[72] J. D. Gerson, L. J. Cheng, and J. W. Corbett, "Identification of Si-Fe deep level states," Journal of Applied Physics, vol. 48, article 4821, 1977.

[73] K. Graff and H. Piper, "Semiconductor Si-1981," H. R. Huff, R. J. Kriegler, and Y. Takeishi, Eds., p. 331, The Electrochemical Society, Pennington, NJ, USA, 1981.

[74] E. Ohta and M. Sakata, "Thermal emission rates and capture cross sections of majority carriers at vanadium centers in silicon," Solid-State Electron, vol. 23, pp. 759-764, 1980.

[75] H. Feichtinger, J. Waltl, and A. Gschwandtner, "Localization of the $\mathrm{Fe}^{\circ}$-level in silicon," Solid State Communications, vol. 27, pp. 867-871, 1978.

[76] H. Feichtinger and R. Czaputa, "Energy levels and solubility of interstitial chromium in silicon," Applied Physics Letters, vol. 39, article 706, 1981.

[77] J. W. Chen and A. G. Milnes, "Energy levels in silicon," Annual Review of Materials Research, vol. 10, pp. 157-228, 1980.

[78] E. R. Weber, “Transition metals in silicon," Applied Physics A, vol. 30, pp. 1-22, 1983.

[79] B. Mitricǎ, M. Petcu, A. Saftoiu et al., "Investigation of cosmic ray muons with the WILLI detector compared with the predictions of theoretical models and with semi-analytical formulae," Nuclear Physics B, vol. 196, pp. 462-465, 2009.

[80] A. Sterian and P. Sterian, "Mathematical models of dissipative systems in quantum engineering," Mathematical Problems in Engineering, vol. 2012, Article ID 347674, 12 pages, 2012.

[81] A. S. Grove, Physics and Technology of Semiconductor Devices, John Wiley, New York, NY, USA, 1967.

[82] S. M. Sze, Physics of Semiconductor Devices, John Wiley, New York, NY, USA, 2nd edition, 1981.

[83] R. N. Hall, "Electron-hole recombination in germanium," Physical Review, vol. 87, p. 387, 1952.

[84] W. Shockley and W. T. Read, "Statistics of the recombinations of holes and electrons," Physical Review, vol. 87, pp. 835-842, 1952.

[85] C. Sah, R. Noyce, and W. Shockley, "Carrier generation and recombination in $p-n$ junction and $p-n$ junction characteristics," Proceedings of the IRE, vol. 45, pp. 1228-1243, 1957.

[86] D. Mcdonald and L. J. Geerligs, "Recombination activity of interstitial iron and other transition metal point defects in $p$ and $n$-type crystalline silicon," Applied Physics Letters, vol. 85, no. 18, pp. 4061-4063, 2004.

[87] G. Bemski, "Recombination properties of gold in silicon," Physical Review, vol. 111, pp. 1515-1518, 1958. 
[88] K. Graff, Metal Impurities in Silicon-Device Fabrication, vol. 24, Springer, Berlin, Germany, 1999.

[89] T. Roth, P. Rosenitz, S. Diez et al., "Electronic properties and dopant pairing behavior of manganese in boron-doped silicon," Journal of Applied Physics, vol. 102, Article ID 103716, 8 pages, 2007.

[90] J. E. Birkholz, K. Bothe, D. Mcdonald, and J. Schmidt, "Electronic properties of iron-boron pairs in crystalline silicon by temperature- and injection-level-dependent lifetime measurements," Journal of Applied Physics, vol. 97, Article ID 103708, 2005.

[91] Y. K. Kwon, T. Ishikawa, and H. Kuwano, "Properties of platinum-associated deep levels in silicon," Journal of Applied Physics, vol. 63, pp. 1055-1058, 1987.

[92] A. N. Larsen and A. Mesli, "The hidden secrets of the E-center in Si and Ge," Physica B, vol. 401-402, pp. 85-90, 2007.

[93] B. B. Pondyal, K. R. McIntosh, D. H. Mcdonald, and G. Coletti, "Temperature dependent $e^{-}$and $h$ capture cross sections of $M o$ in silicon," in Proceedings of the 24th European Photo-Voltaic Solar Energy Conference, Germany, 2009.

[94] J. Schmidt, R. Krain, K. Bothe, G. Pensl, and S. Beljakava, "Recombination activity of interstitial chromium and chromiumboron pairs in Si," Journal of Applied Physics, vol. 102, Article ID 123701, 2007.

[95] P. Rosenitz, T. Roth, S. Diez, D. Mcdonald, and S. W. Glunz, "Detailed studies of manganese in silicon using lifetime spectroscopy and deep-level transient spectroscopy," in Proceedings of the 22nd European Conference on Photo-Voltaic Solar Energy (EU-PVSEC '07), pp. 1480-1483, Milan, Italy, September 2007. 

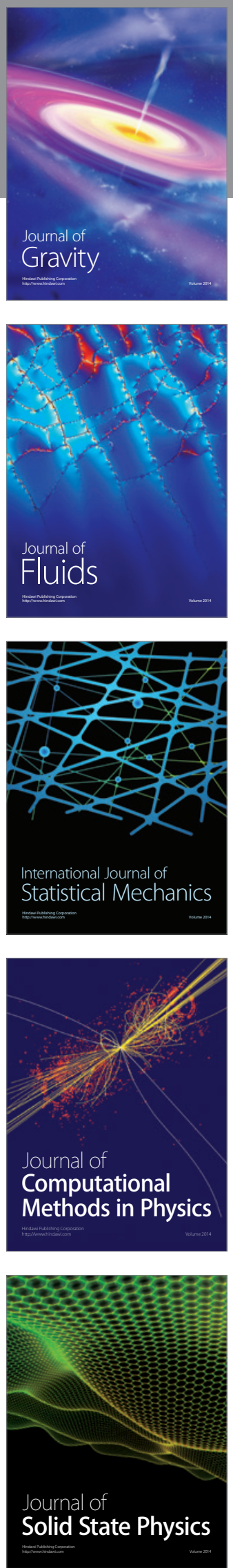

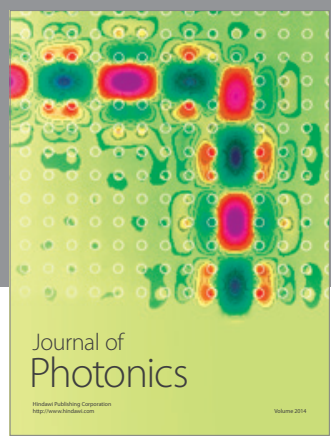

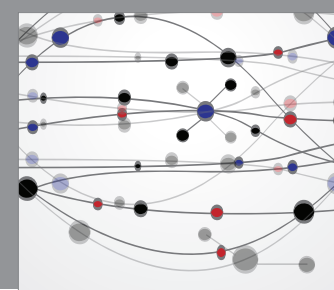

The Scientific World Journal

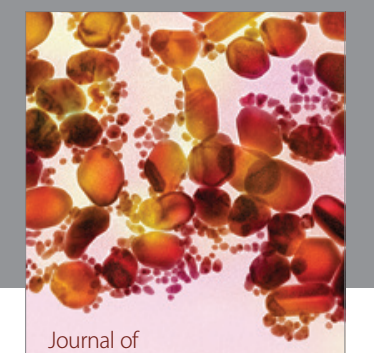

Soft Matter
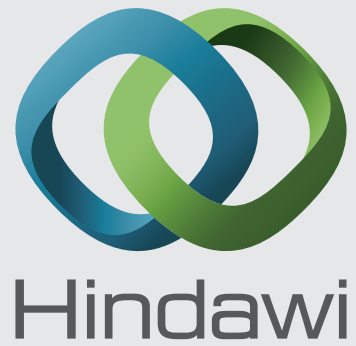

Submit your manuscripts at

http://www.hindawi.com
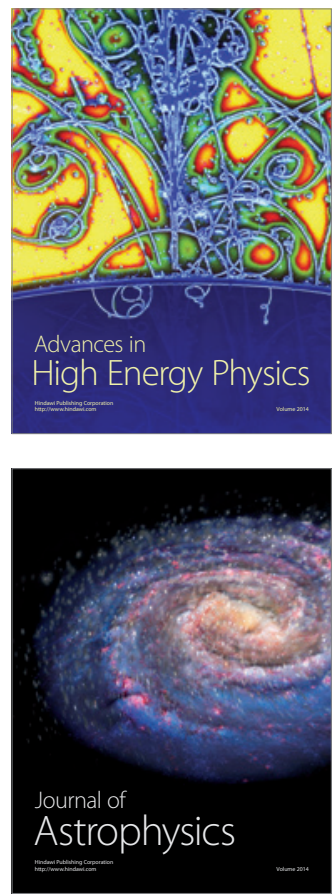
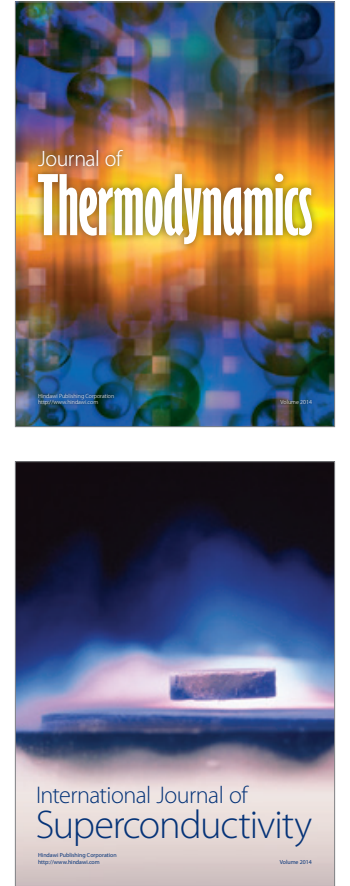
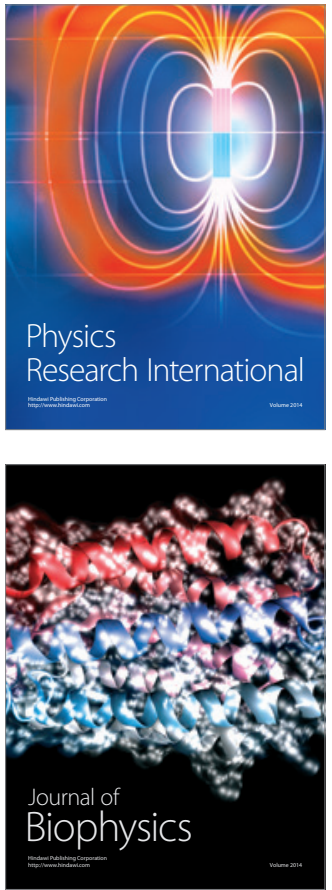
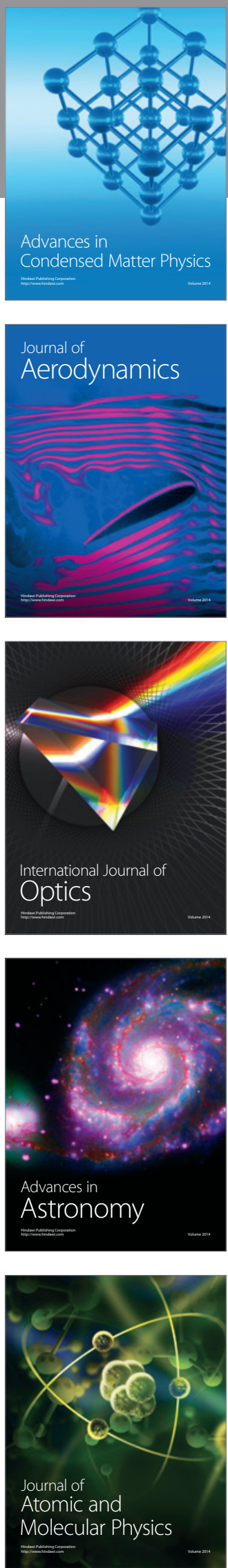